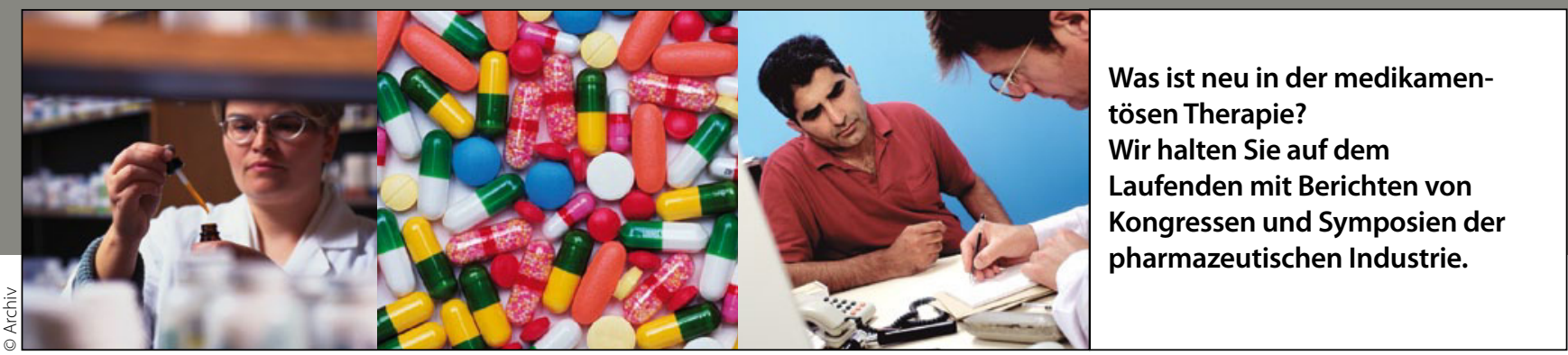

\title{
Asthma und COPD
}

\section{Je schwerer, desto weniger zu unterscheiden}

- Asthma beginnt meist in der Jugend, betrifft Nichtraucher, tritt anfallsweise auf und spielt sich in den großen Atemwegen ab. Die Limitation des Atemflusses im Anfall ist voll reversibel. Dagegen tritt die COPD in höherem Alter auf und betrifft vor allem Raucher. Die Obstruktion ist fixiert und verschlechtert sich progredient. Kleine Atemwege und das Parenchym sind an dem Prozess beteiligt, und es kommt zu Hyperinflation und Diffusionsstörungen.

Im klinischen Alltag stellt sich dennoch oft die Frage, in welche Kategorie ein Patient einzuordnen ist. „Das Problem ist, dass wir in klinischen Studien Phänotypen untersuchen, die wir im klinischen Alltag nicht sehen", so Prof. Winfried Randerath, Solingen.

\section{Viele Überschneidungen}

Zwischen Asthma und COPD gibt es in der Realität reichlich Überschneidungen. Das gilt insbesondere für das schwere bzw. refraktäre Asthma, das durch eine zunehmende chronische Inflammation und Obstruktion gekennzeichnet ist und deren Reversibilität immer mehr verloren geht.

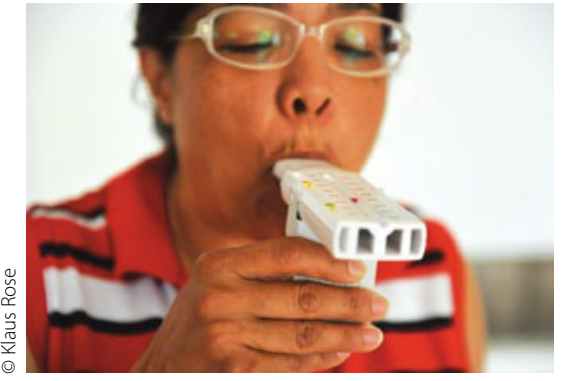

Oft stellt sich die Frage: In welche Kategorie den Patienten einordnen?

Häufig sind dann nicht nur größere, sondern auch kleinere Atemwege involviert. Im CT-Bild sieht man eine Zunahme der Wanddicke der Bronchien wie beim Bronchitistyp der COPD, d. h. es wird immer schwieriger, COPD und Asthma im CT zu unterscheiden. Beim schweren Asthma ist das Lumen der Bronchien durch die Wandverdickung wie bei der COPD vermindert.

Die COPD teilt man grob in Emphysemund Atemwegstyp ein. Je nach Schwere ist aber auch mehr oder weniger Entzündung im Spiel. Dabei überwiegen Neutrophile und Makrophagen, während beim Asthma die eosinophile Entzündung dominiert. In beiden Fällen sind auch Leukotriene involviert.

Wie Prof. Christian Virchow, Rostock, erklärte, kann der Leukotrienrezeptorantagonist Montelukast (Singulair ${ }^{\circledast}$ ) die Kontrolle eines persistierenden Asthma bronchiale verbessern, wenn dies durch inhalative Steroide und langwirksame Betamimetika nicht ausreichend möglich ist. Dies hat die MONICA-Studie (Montelukast in chronic asthma) erneut bestätigt.

Die zusätzliche antientzündliche Therapie führte zu einer signifikanten und anhaltenden Zunahme des Score im AsthmaControl-Test (ACT). Besonders deutlich profitierten gemäß einer Subgruppenanalyse Patienten mit niedrigen ACT-Ausgangswerten, mit gleichzeitiger allergischer Rhinitis, jüngere Patienten mit kürzerer Asthmaanamnese und Patienten, die nur mit Steroiden behandelt wurden.

- Angelika Bischof

Quelle: Symposium „Asthma \& COPD“, DGPKongress, Dresden, April 2011 (Veranstalter: MSD Sharp \& Dohme)

\section{Xanthin-Oxidase-Hemmer ist Kandidat für Galenus-Preis \\ Febuxostat senkt die Harnsäure bei Gicht effizient}

— Im Oktober verleiht die Ärzte Zeitung den Galenus-von-Pergamon-Preis 2011 für eine herausragende Arzneimittelinnovation. Zu den Bewerbern gehört auch der nicht-purinische Xanthin-Oxidase-Hemmer Febuxostat (Adenuric ${ }^{\circledast}$ ) von BerlinChemie.
Seit der Markteinführung des Präparates 2010 steht Ärzten eine innovative Option zur Absenkung der Harnsäure bei Gicht zur Verfügung. Abgesehen vom Management akuter Anfälle ist eine effektive und dauerhafte Absenkung der Harnsäurekonzentration im Serum die wichtigste und eine obendrein kausal wirksame Therapie.

Die Europäische

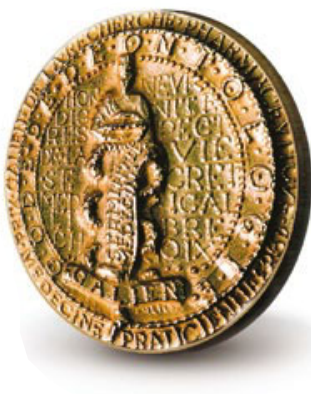
Rheumaliga (EULAR) empfiehlt bei Patienten mit manifester Gicht eine dauerhafte Harn- 